\title{
Avaliação para tolerância ao estresse hídrico em feijão
}

\author{
Naine Martins do Vale ${ }^{1 *}$ \\ Leiri Daiane Barili ${ }^{1}$ \\ Diane Simon Rozzeto \\ Jussara Cristina Stinghin ${ }^{1}$ \\ Jefferson Luís Meirelles Coimbra ${ }^{1}$ \\ Altamir Frederico Guidolin ${ }^{1}$ \\ Mauricio Marini Köop ${ }^{2}$ \\ ${ }^{1}$ Instituto de Melhoramento e Genética Molecular - IMEGEM \\ Centro de Ciências Agroveterinárias, Universidade do Estado de Santa Catarina \\ Avenida Luiz de Camões, 2090, Bairro Conta Dinheiro, CEP 88520-000, Lages - SC, Brasil \\ ${ }^{2}$ Universidade Federal de Pelotas \\ * Autor para correspondência \\ nainemartinsdovale@hotmail.com
}

Submetido em 15/08/2011

Aceito para publicação em 16/04/2012

\section{Resumo}

Este trabalho teve como objetivo avaliar genótipos de feijão e classificá-los em tolerantes e sensíveis ao estresse hídrico por meio de avaliação de características morfológicas para utilização em blocos de cruzamentos bem como no estudo da expressão gênica. Foram avaliados nove genótipos de feijão: IAPAR14, IAPAR81, Pérola, IPRColibri, IPRJuriti, IPRChopim, IPRGralha, IPRTiziu e IPRUirapuru. Os genótipos foram submetidos a duas condições hídricas: i) irrigação conforme a necessidade hídrica da cultura durante todo o ciclo e ii) irrigação conforme a necessidade hídrica da cultura até o aparecimento do primeiro botão floral, seguida de supressão da irrigação por 15 dias. O delineamento experimental foi de blocos casualizados com três repetições. As características avaliadas foram: i) estatura de planta; ii) diâmetro do caule; iii) número de legumes por planta; iv) número de grãos por legume; v) comprimento radicular e vi) massa seca radicular. O caráter diâmetro do caule não deve ser utilizado para discriminar os genótipos de feijão como tolerantes ou suscetíveis a falta de água. $\mathrm{O}$ genótipo Pérola foi superior para a maioria das características avaliadas, desta forma foram classificados como tolerante ao estresse hídrico no período do florescimento. Os genótipos IAPAR81 e IPRJuriti apresentaram os piores resultados para a maioria das características avaliadas, sendo classificados como suscetíveis ao estresse hídrico no período do florescimento.

Palavras-chave: Caracteres morfológicos; Estresse abiótico; Expressão gênica; Phaseolus vulgaris L.

\section{Abstract}

Evaluation of tolerance to water stress in beans. The goal of this study was to evaluate the genotypes of beans, and to sort them into groups that are tolerant and sensitive to water stress, by assessing their morphological characteristics for use in blocks of crosses and the study of gene expression. We evaluated nine bean genotypes: 
IAPAR 14, IAPAR 81, Pérola, IPR Colibri, IPR Juriti, IPR Chopim, IPR Gralha, and IPR Tiziu IPR Uirapuru. The genotypes were subjected to two irrigation conditions: i) irrigation water as needed throughout the culture cycle and ii) irrigation water as needed until the appearance of the first bud, followed by no irrigation water for 15 days. The experimental design was in randomized blocks with three replications. The characteristics evaluated were: i) plant height; ii) stem diameter, iii) number of pods per plant, iv) number of grains per pod, v) root length and vi) root dry mass. Stem diameter should not be used to determine if bean genotypes are tolerant or susceptible to water shortages. The results for the Pérola genotype were the highest for most of the characteristics evaluated, and, for this reason, it was classified as tolerant to water stress during flowering. The genotypes IAPAR and 81 IPR Juriti had the lowest results for the most features and were classified as susceptible to water stress during flowering.

Key words: Abiotic stress; Gene expression; Morphologic characters; Phaseolus vulgaris L.

\section{Introdução}

A cultura do feijão representa grande importância a nível mundial e nacional. No Brasil, é cultivado por pequenos, médios e grandes agricultores, com produção anual total de 3,4 milhões de toneladas (CONAB, 2010). Atualmente no Brasil, apesar da qualidade tecnológica empregada, não se observam ganhos substanciais na produtividade média de feijão, estando esta em cerca de $842 \mathrm{~kg} \cdot \mathrm{ha}^{-1}$ (IBGE, 2010). Esse valor pode ser considerado baixo se comparado ao rendimento de $1.800 \mathrm{~kg} \cdot \mathrm{ha}^{-1}$ ou superior, que pode ser obtido com uso da irrigação tecnicamente conduzida (OLIVEIRA et al., 2005).

Assim o baixo rendimento tem sido atribuído a cultivares pouco produtivas, incidência de pragas e doenças, e principalmente devido às diferentes condições edafoclimáticas nas quais o feijão é cultivado, sendo que entre os fatores climáticos, a seca é o que mais contribui para o insucesso das culturas (GUIMARÃES et al., 2006; RAMALHO et al., 2009), acarretando em baixo rendimento de grãos (OLIVEIRA et al., 2005).

Conforme destacado anteriormente, a seca é um dos principais problemas no feijão, bem como em grande parte das plantas cultivadas em todo o mundo. É estimado, por exemplo, que na cultura do feijão na África, cerca de 300 mil toneladas de feijão são perdidos anualmente devido à seca (RAMALHO et al., 2009). O feijão é considerado uma espécie com pouca tolerância a estresses hídricos, sendo que $60 \%$ do seu cultivo no planeta está submetido a este fator, tornando a seca o maior redutor da produtividade (AGUIAR et al., 2008; BEEBE et al., 2008). A baixa disponibilidade de água no solo é um fator limitante na produção do feijão, especialmente em três estádios críticos, que são a germinação, florescimento e enchimento de grãos (SORATTO et al., 2003).

Sendo o estresse hídrico um dos fatores que contribuem para a diminuição do rendimento, é extremamente importante o modo como as plantas respondem aos estresses abióticos, pois esta resposta é crucial para o rendimento de grãos, sendo que o ambiente desfavorável constitui o fator mais significativo conduzindo a substancial e incalculável diminuição na produtividade (CUSTÓDIO et al., 2009). No entanto, algumas práticas de manejo podem contribuir para o aumento da produtividade em condições de estresses abióticos, entretanto, o maior progresso tem sido obtido através do melhoramento (SINGH, 1995), pois as cultivares tolerantes tem a capacidade de interligar uma diversidade de sinais ambientais a sinais metabólicos que regulam a expressão gênica durante o estresse(CUSTÓDIO et al., 2009), assim possibilitando a sua sobrevivência.

Uma das maneiras de remediar, em curto prazo, o problema que a cultura do feijão enfrenta devido à deficiência hídrica é a caracterização em ambiente controlado para que os tolerantes possam ser utilizados em programas de melhoramento como fonte de tolerância ao estresse hídrico para associar essa característica a outras dos demais genótipos que compõem os blocos de cruzamentos. Além disso, genótipos contrastantes podem ser uma importante fonte para estudos genéticos para a identificação dos genes correspondentes e a avaliação da expressão gênica. 
O presente trabalho teve como objetivo avaliar genótipos de feijão e classificá-los em tolerantes e sensíveis ao estresse hídrico por meio de características morfológicas, para posterior utilização em blocos de cruzamentos bem como no estudo da expressão gênica.

\section{Material e Métodos}

Para a caracterização ao estresse hídrico foram utilizados nove genótipos de feijão registrados no Serviço Nacional de Proteção de Cultivares (SNPC), sendo cinco do grupo comercial carioca: (IAPAR 14, IAPAR 81, Pérola, IPR Colibri e IPR Juriti) e quatro do grupo preto: (IPR Chopim, IPR Gralha, IPR Tiziu e IPR Uirapuru). Os cultivares foram selecionados com base em informações obtidas de seus descritores, quanto à tolerância ou não ao estresse hídrico.

O experimento foi conduzido durante todo o ciclo em casa de vegetação. A semeadura foi realizada em baldes plásticos contendo de $10 \mathrm{~kg}$ de solo, o qual foi coletado na aérea experimental, sendo este classificado como Cambissolo Húmico. Depois de cheios, os baldes foram pesados, com a finalidade de uniformizar o peso de solo. Foram semeadas cinco sementes por balde, para garantir o número de planta desejado, e mantidas, até o momento do aparecimento da primeira folha trifoliolada (V3), quando foi realizado o raleio mantendo duas plantas por balde.

No momento da semeadura foi realizada a correção do solo de acordo com a análise química, sendo incorporado seis gramas de NPK na formulação 5:20:20 em cada balde. $\mathrm{O}$ pH do solo de 5,7 não necessitou de correção. A adubação de cobertura foi realizada com ureia ( $3 \mathrm{~g}$ por balde) quando as plantas estavam no estagio V3. Sempre que necessário foram retiradas as plantas invasoras de forma manual.

Os genótipos foram submetidos a duas condições hídricas. Na condição 1 , os genótipos foram irrigados conforme a necessidade hídrica da cultura durante todo o ciclo. Na condição 2, os genótipos foram irrigados conforme a necessidade hídrica da cultura até o aparecimento do primeiro botão floral (R6), quando a irrigação foi suspensa por um período de 15 dias. $\mathrm{O}$ início da suspensão da irrigação foi diferente para cada cultivar, respeitando o inicio do florescimento de cada uma. Após esse período a irrigação foi retomada conforme a necessidade hídrica da cultura até a conclusão do ciclo. Metodologia semelhante foi utilizada por diversos autores como Aguiar et al. (2008).

O delineamento experimental utilizado foi de blocos ao acaso com três repetições, onde cada balde contendo duas plantas constituía uma repetição, dessa forma foram avaliadas seis plantas por genótipo em cada condição hídrica. Foram avaliadas ao final do ciclo características da parte aérea bem como de raízes, sendo elas: $i)$ estatura de planta $(\mathrm{cm})$; ii) diâmetro do caule (mm); iii) número de legumes por planta; iv) número de grãos por legume; v) comprimento da raiz (cm) e vi) massa seca da raiz $(\mathrm{g})$.

Para a avaliação do sistema radicular, foi realizado arranquio das plantas, iniciando-se com um leve revolvimento do solo com hastes pontiagudas e, em seguida, retirada das plantas do solo. A seguir, as raízes foram lavadas em água corrente e secas com papel toalha, para serem realizadas as medições do comprimento do eixo principal com auxilio de trena calibrada em milímetros. Em seguida, individualmente, as raízes foram colocadas em sacos de papel e levadas à estufa por $24 \mathrm{~h}$ a temperatura de $48^{\circ} \mathrm{C}$ para determinação da massa seca. Passado este período realizou-se a pesagem em balança digital com precisão de $0,001 \mathrm{~g}$.

O modelo estatístico utilizado neste experimento foi:

$$
Y_{i j k}=m+b_{i} g_{j}+c h_{k}+g_{j} c h_{k}+e_{i j k}
$$

Efeitos expressos na equação do modelo estatístico: m: média; $b_{i}$ : efeito do bloco; $g_{j}$ : efeito do genótipo; $\mathrm{ch}_{\mathrm{k}}$ : efeito da condição hídrica e $\mathrm{e}_{\mathrm{ijk}}$ : erro experimental.

Os dados foram submetidos à análise de variância pelo teste $\mathrm{F}$ ao nível de 5\% de probabilidade de erro e posterior teste de comparação de médias (ScoottKnott), a fim poder caracterizá-los como tolerantes e sensíveis ao estresse hídrico no período do florescimento, utilizando o programa SAS. A divergência genética foi estimada por meio da estatística de Mahalanobis $\left(\mathrm{D}^{2}\right)$ e por meio da matriz de dissimilaridade genética, as 
quais são estatísticas multivariadas. O dendrograma foi obtido utilizando o método de agrupamento UPGMA (Unweighted Pair-Group Method Using Arithmetic Averages) (ROHLF, 2000), utilizando os programas Genes e NTSys.

\section{Resultados}

A partir dos resultados, pode ser verificado que para todas as características avaliadas, houve efeito significativo da interação genótipo $x$ condição hídrica (g vs. ch), exceto para o diâmetro do caule, o qual não apresentou efeito significativo para nenhuma das fontes de variação avaliadas (Tabela 1). Deste modo, a decomposição dos graus de liberdade foi efetuada através de contrastes (comparação entre o genótipo submetido ao estresse hídrico vs. genótipo sem estresse) que revelou efeito significativo para todas as variáveis avaliadas, evidenciando que todos os genótipos apresentam comportamento diferenciado em relação às condições de potencial de água no solo às quais foram submetidos. Este procedimento não permitiu a discriminação dos genótipos, a qual foi realizada por meio de teste de comparação de médias para identificar e caracterizar os sensíveis e tolerantes.

A Tabela 2 apresenta as médias dos genótipos no tratamento em estresse hídrico. Sendo que estas médias foram as utilizadas para a realização dos contrastes de cada genótipos nas duas condições (condição normal de irrigação e estresse hídrico), esses dados permitem verificar que quando os genótipos estavam na condição normal de irrigação apresentaram um comportamento não muito discrepantes entre eles.

A partir das médias das seis características avaliadas dos nove genótipos de feijão submetidos ao estresse hídrico, pode ser observado que o genótipo Pérola apresentou o maior valor para estatura de planta $(0,89 \mathrm{~m})$, quando comparado aos demais genótipos,

TABELA 1: Resumo da análise de variância para os nove genótipos submetidos a duas condições de potencial hídrico do solo, para as variáveis estatura (EST), diâmetro do caule (DC), número de legumes por planta (NLP), número de grãos por legume (NGL), comprimento da raiz (CR) e massa seca da raiz (MSR).

\begin{tabular}{lccccccc}
\hline \multirow{2}{*}{ F.V. } & \multirow{2}{*}{ G.L. } & \multicolumn{7}{c}{ Quadrado Médio } \\
\cline { 3 - 8 } & & EST & DC & NLP & NGL & CR & MSR \\
\hline Genótipo (G) & 8 & $2149,51^{*}$ & 0,037 & $6,85^{*}$ & $11,49^{*}$ & $31,82^{*}$ & $0,020^{*}$ \\
Condição Hídrica (CH) & 1 & $1940,98^{*}$ & 0,024 & $10,51^{*}$ & $4,04^{*}$ & $61,88^{*}$ & $0,014^{*}$ \\
G x CH & 8 & $835,74^{*}$ & 0,008 & $3,04^{*}$ & $0,25^{*}$ & $20,45^{*}$ & $0,005^{*}$ \\
Bloco & 2 & 198,45 & 0,005 & 4,13 & 0,09 & 7,65 & 0,003 \\
\hline Erro & 34 & 261,30 & 0,003 & 2,12 & 0,14 & 17,33 & 0,004 \\
CV $(\%)$ & - & 32,26 & 18,76 & 17,78 & 10,14 & 24,34 & 27,80 \\
\hline
\end{tabular}

${ }^{*}$ Significativo a 5\% de probabilidade de erro pelo teste de F.

TABELA 2: Médias para os nove genótipos na condição normal de irrigação, para as variáveis, estatura de planta (EST) em $\mathrm{m}$, diâmetro do caule (DC) em m, número de legumes por planta (NLP), número de grãos por legume (NGL), comprimento da raiz (CR) em m massa seca da raiz (MSR) em kg.

\begin{tabular}{lcccccc}
\hline \multirow{2}{*}{\multicolumn{1}{c}{ Genótipo }} & \multicolumn{7}{c}{ Característica } \\
\cline { 2 - 6 } & EST & DC & NLP & NGL & CR & MSR \\
\hline Pérola & 0,95 & 0,0034 & 14,99 & 7,65 & 0,26 & 0,00041 \\
IPR Chopim & 0,81 & 0,0044 & 13,28 & 6,54 & 0,24 & 0,00032 \\
IPR Uirapuru & 0,65 & 0,0039 & 13,66 & 4,33 & 0,21 & 0,00039 \\
IPR Colibri & 0,66 & 0,0031 & 13,71 & 7,21 & 0,14 & 0,00012 \\
IPR Tiziu & 0,72 & 0,0037 & 12,67 & 7,19 & 0,17 & 0,00038 \\
IAPAR 14 & 0,87 & 0,0036 & 14,93 & 4,11 & 0,16 & 0,00029 \\
IPR Gralha & 0,80 & 0,0032 & 13,69 & 6,93 & 0,19 & 0,00027 \\
IAPAR 81 & 0,78 & 0,0037 & 13,76 & 7,75 & 0,12 & 0,00021 \\
IPR Juriti & 0,69 & 0,0036 & 14,27 & 5,29 & 0,18 & 0,00026 \\
\hline
\end{tabular}


sendo a sua média significativamente diferente dos demais genótipos. Em contrapartida, o genótipo IPR Juriti $(0,31 \mathrm{~m})$, apresentou pequeno desenvolvimento da parte aérea, tendo a menor estatura de planta, a qual diferiu significativamente frente aos demais genótipos (Tabela 3).

Quanto à variável número de legumes por planta (NLP), observa-se que o genótipo Pérola obteve a melhor performance $(11,87)$, seguido do genótipo IPR Chopim $(10,33)$ onde estes foram iguais, porém diferiram de todos os demais, os quais diferiram entre si. Novamente, para a variável número de grãos por legume (NGL), o genótipo Pérola obteve o melhor desempenho $(5,87)$, porém desta vez seguido do IPR Tiziu $(4,38)$. Para este caráter, o Pérola apresentou diferença significativa em relação à segunda maior média (IPR Tiziu). Em contrapartida, o genótipo IAPAR 81 teve desempenho inferior apresentando um baixo $\operatorname{NLP}(6,52)$, acompanhado do IPR Tiziu e IPR Gralha (6,69 e 6,52, respectivamente), sendo que esses três genótipos não diferiram significativamente entre si, porém diferiram dos genótipos com maior média. O IPR Juriti apresentou o mesmo comportamento do NLP para a característica NGL $(3,92)$, mostrando a pior média frente aos outros genótipos e essa sendo diferente significativamente.

Ainda, a partir dos resultados, pode ser verificado que para as características radiculares, como o comprimento da raiz e massa seca da raiz, diferentes genótipos apresentaram valores elevados, como IPR Uirapuru para CR $(0,21 \mathrm{~m})$ e Pérola para MSR $(0,00035 \mathrm{~kg})$ (Tabela 2$)$, sendo que o IPR Uirapuru obteve diferença significativa em relação aos demais genótipos para CR. O Pérola não diferiu estatisticamente do IPR Chopim, IPR Uirapuru e IPR Tiziu para MSR que apresentaram valores elevados para a característica. Em contrapartida o genótipo IAPAR 81 apresentou o pior desempenho para ambas as características $(0,12 \mathrm{~m}$ para CR e $0,00017 \mathrm{~kg}$ para MSR), diferindo significativamente de todos os genótipos para CR e MSR.

Analisando o dendrograma (Figura 1), que trata do agrupamento dos genótipos em condições de estresse hídrico, pode ser verificado que houve a formação de dois grupos: $i$ ) IPR Juriti e IAPAR 81 e ii) IAPAR 14, IPR Tiziu, IPR Gralha, IPR Colibri, IPR Uirapuru e IPR Chopim, e um genótipo isolado, o Pérola. A superioridade apresentada para a maioria dos caracteres avaliados em condições de estresse hídrico conferiu ao genótipo Pérola este destaque em relação aos demais genótipos, evidenciando sua dissimilaridade. Da mesma forma, o desempenho inferior do IPR Juriti e IAPAR 81, evidenciado pelos baixos valores dos caracteres avaliados, conferiram a eles a inclusão no primeiro grupo bem como, grande dissimilaridade com o genótipo Pérola o qual se situou no lado oposto do dendrograma.

Em condições ideais de irrigação a disparidade entre os genótipos estudados resulta da divergência

TABELA 3: Teste de médias para os nove genótipos submetidos a estresse hídrico, para as variáveis, estatura de planta (EST) em m, diâmetro do caule (DC) em m, número de legumes por planta (NLP), número de grãos por legume (NGL), comprimento da raiz (CR) em m massa seca da raiz (MSR) em kg.

\begin{tabular}{lcccccc}
\hline \multirow{2}{*}{ Genótipo } & \multicolumn{5}{c}{ Característica } \\
\cline { 2 - 6 } & EST & DC & NLP & NGL & CR & MSR \\
\hline Pérola & $0,89 \mathrm{~A}$ & $0,0032 \mathrm{~A}$ & $11,87 \mathrm{~A}$ & $5,87 \mathrm{~A}$ & $0,17 \mathrm{~B}$ & $0,00035 \mathrm{~A}$ \\
IPR Chopim & $0,74 \mathrm{~B}$ & $0,0038 \mathrm{~A}$ & $10,33 \mathrm{~A}$ & $4,24 \mathrm{~B}$ & $0,18 \mathrm{~B}$ & $0,00031 \mathrm{~A}$ \\
IPR Uirapuru & $0,48 \mathrm{C}$ & $0,0037 \mathrm{~A}$ & $8,17 \mathrm{~B}$ & $4,33 \mathrm{~B}$ & $0,21 \mathrm{~A}$ & $0,00029 \mathrm{~A}$ \\
IPR Colibri & $0,46 \mathrm{C}$ & $0,0026 \mathrm{~A}$ & $8,17 \mathrm{~B}$ & $4,19 \mathrm{~B}$ & $0,14 \mathrm{C}$ & $0,00012 \mathrm{C}$ \\
IPR Tiziu & $0,41 \mathrm{D}$ & $0,0036 \mathrm{~A}$ & $6,63 \mathrm{C}$ & $4,38 \mathrm{~B}$ & $0,17 \mathrm{~B}$ & $0,00027 \mathrm{~A}$ \\
IAPAR 14 & $0,41 \mathrm{D}$ & $0,0033 \mathrm{~A}$ & $8,30 \mathrm{~B}$ & $4,13 \mathrm{~B}$ & $0,16 \mathrm{C}$ & $0,00021 \mathrm{~B}$ \\
IPR Gralha & $0,38 \mathrm{D}$ & $0,0031 \mathrm{~A}$ & $6,69 \mathrm{C}$ & $4,35 \mathrm{~B}$ & $0,19 \mathrm{~B}$ & $0,00022 \mathrm{~B}$ \\
IAPAR 81 & $0,38 \mathrm{D}$ & $0,0034 \mathrm{~A}$ & $6,52 \mathrm{C}$ & $4,21 \mathrm{~B}$ & $0,12 \mathrm{D}$ & $0,00017 \mathrm{~B}$ \\
IPR Juriti & $0,31 \mathrm{E}$ & $0,0035 \mathrm{~A}$ & $8,25 \mathrm{~B}$ & $3,92 \mathrm{C}$ & $0,18 \mathrm{~B}$ & $0,00019 \mathrm{~B}$ \\
\hline
\end{tabular}

Médias seguidas pela mesma letra indicam não haver diferença significativa a 5\% de probabilidade pelo teste de ScoottKnott. 
genética entre eles. No segundo dendrograma (Figura 2), verifica-se a formação de um grande grupo onde estão os genótipos: IAPAR 81, IPR Juriti, Pérola, IPR Uirapuru, IPR Tiziu e IPR Gralha (grupo 1) e um grupo com apenas dois genótipos: IPR Chopim e IAPAR $14 \mathrm{e}$ um genótipos isolado, o IPR Colibri (grupo 2).

Deve ser evidenciado que na comparação entre as duas figuras, bem como na composição dos grupos formados, onde se verifica que os genótipos contrastantes na Figura 1, em condições de estresse hídrico (Pérola $x$ IAPAR 81 e IPR Juriti), em condições ideais de crescimento situaram-se no mesmo grupo na Figura 2, ressaltando que a dissimilaridade entre estes genótipos em condições de estresse hídrico estar relacionada à superioridade do genótipo Pérola, visto que apresentou elevadas médias para os caracteres avaliados, diferentemente da performance apresentada pelos genótipos IAPAR 81 e IPR Juriti.

FIGURA 1: Dendrograma referente aos nove genótipos de feijão comum que foram submetidos ao estresse hídrico, utilizando o índice de dissimilaridade de Mahalanobis $\left(\mathrm{D}^{2}\right)$ por meio do método de agrupamento UPGMA.

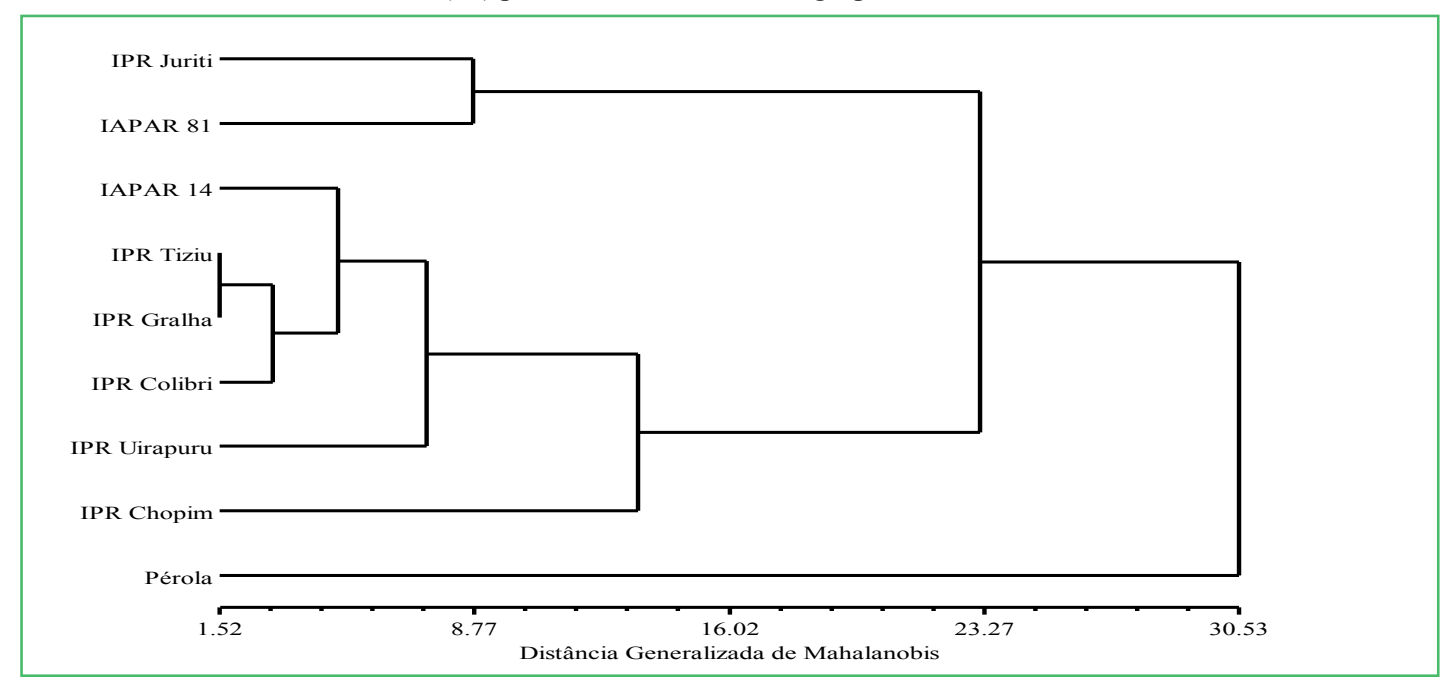

FIGURA 2: Dendrograma referente aos nove genótipos de feijão comum que não foram submetidos ao estresse hídrico, utilizando o índice de dissimilaridade de Mahalanobis $\left(\mathrm{D}^{2}\right)$ por meio do método de agrupamento UPGMA.

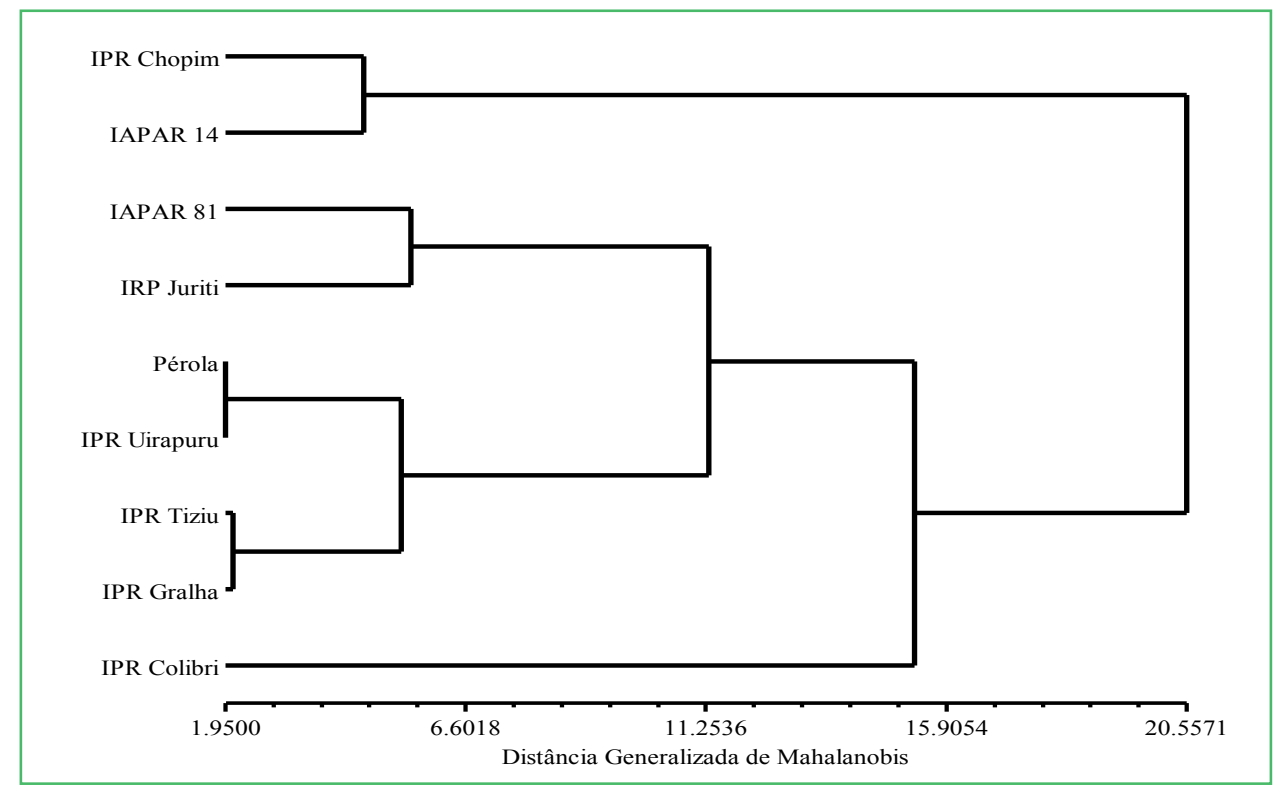




\section{Discussão}

O caráter diâmetro de caule (DC) é de grande importância para a arquitetura da planta, visto que caules espessos e rígidos podem evitar o acamamento, entretanto, conforme supracitado, não houve diferenças significativas para nenhuma das fontes de variação (Tabela 1). Em função disso, esta pode não ser uma variável eficiente na discriminação de genótipos de feijão, quando são submetidos à deficiência hídrica. A utilização do teste $F$ para fatores com mais de um grau de liberdade, permite obter informações gerais, relacionadas com o comportamento médio dos tratamentos (BANZATTO; KRONKA, 2006). No entanto, os desdobramentos ortogonais dos graus de liberdade de tratamentos permitem obter informações mais específicas, relacionadas com o comportamento médio de cada um dos componentes do desdobramento (NESI; GARCIA, 2005).

Desta forma os contrastes efetuados a fim de desdobrar os graus de liberdade da interação demonstraram que todos os genótipos foram diferentes de suas testemunhas e estes resultados corroboram com o esperado, pois, quando o genótipo é submetido a uma condição de estresse o valor de suas características apresenta um decréscimo, mesmo para genótipos tolerantes. Molina et al. (2001) observaram que a supressão hídrica, ocorrida durante as fases de florescimento, ocasiona redução para a maioria das características agronômicas do feijão.

Os resultados encontrados na literatura quanto ao comportamento do caráter estatura de plantas são divergentes, sendo que, em alguns casos os genótipos apresentaram redução da estatura de planta devido ao fato do estresse hídrico reduzir o turgor das células e, consequentemente, o seu crescimento (COSTA et al., 2008), porém, em outros ocorre um aumento, quando submetidos ao estresse hídrico (AGUIAR et al., 2008). Ainda, segundo os mesmos autores, tal resultado pode ser consequência do estiolamento das plantas quando submetidas a essas condições, sendo que, os genótipos que apresentaram redução da característica não possuem atributos de tolerância ao estresse hídrico, desta forma, EST é uma característica apropriada a ser utilizada na distinção de genótipos contrastantes e assim auxiliar na identificação dos tolerantes. Desta forma, verifica-se que o genótipo Pérola, o qual apresentou o maior valor para a característica, opôs-se ao IPR Juriti que apresentou o pior desenvolvimento (Tabela 3), demonstrando assim que o Pérola está indicando ser um genótipo tolerante a seca, o contrário do IPR Juriti, quando comparados aos genótipos utilizados no estudo.

Em decorrência do rendimento de grãos ser a característica mais importante do ponto de vista agrícola e econômico em culturas como o feijão, as avaliações de performance de genótipos tolerantes à seca, são efetuadas mensurando-se as características a ele relacionadas (ACOSTA-GALLEGOS; ADAMS, 1991), no caso os componentes do rendimento.

Desta forma, genótipos que em condições de baixa disponibilidade de água no solo apresentem reduzido NLP e NGL são genótipos que não possuem a capacidade de tolerar o déficit hídrico, como foi observado para o IAPAR 81 e IPR Juriti que apresentaram valores menores para ambas as características (Tabela 3), sendo que estes baixos valores não lhe proporcionaram um rendimento esperado para a cultura. Por outro lado, genótipos que se sobressaem em NLP e NGL são os que certamente possuem habilidade de tolerar períodos de estresse hídrico como é o caso do Pérola, visto que são um dos principais componentes do rendimento. Deste modo, se uma planta mantém o status desejável para NLP e NGL, provavelmente o rendimento será menos afetado, ainda que esteja sob estresse hídrico. Tal fato pode propiciar a redução das perdas no cultivo de feijão em áreas onde a probabilidade de ocorrência de estresse hídrico é grande e assim minimizar perdas na produção final como ocorre quando é feita a utilização de cultivares sensíveis à falta de água (VIBRANS; SCHRAMM, 2009).

As variáveis EST juntamente com NLP e NGL são de extrema importância para o melhoramento vegetal, visto que genótipos que apresentaram superioridade na EST em condições de estresse hídrico são genótipos potenciais a tolerar a falta de água. Os genótipos com maior estatura provavelmente possuem maior capacidade de recuperação após o estresse e assim melhores condições de competição por luz em especial com gramíneas invasoras que na grande maioria são 
plantas $\mathrm{C}_{4}$ e sofrem menos a falta de água. A maior estatura dessas plantas não se refere a plantas maiores do que o ideótipo almejado para a cultura, mas sim plantas que não reduzam drasticamente a estatura em condição de estresse quando comparada a condição ideal de irrigação. As variáveis NLP e NGL também estão correlacionadas de forma positiva com o rendimento de grãos, sendo que, quanto maiores, maior será a produção. De acordo com o citado anteriormente, os resultados da Tabela 3 referentes a EST, NLP e NGL permitem comprovar que os genótipos Pérola e IPR Chopim são promissores quanto a tolerância ao estresse hídrico, pois sobressaíram-se de forma significativa dos demais genótipos, para esses três variáveis.

Considerando todos os órgãos da planta, as raízes são as menos estudadas, entendidas e apreciadas, pelo fato de não poderem ser vistas e, ainda, pelas dificuldades para o seu estudo (HUGHES et al., 1992) e por esse motivo não são avaliadas em larga escala em programas de melhoramento. São elas, contudo que, além de servirem como suportes para a planta, absorvem e translocam água e nutrientes, armazenarem carboidratos (SOUSA et al., 2009), além de servirem como indicadores de genótipos tolerantes ao estresse hídrico.

A característica de tolerância à seca está diretamente relacionada ao comprimento e densidade da raiz (ARUNYANARK et al., 2009), onde, genótipos que apresentam comportamento superior para tais devem ser inclusos em blocos de cruzamentos de programas de melhoramento que visem desenvolver genótipos capazes de tolerar longos períodos de estiagem. Estes genótipos possuem genes relacionados à capacidade de expansão radicular, evitando assim maiores prejuízos a cultura do feijão. Tal comportamento foi verificado nos genótipos IPR Uirapuru que apresentou elevado valor para CR. Para o caráter MSR, os genótipos IPR Uirapuru, IPR Chopim e Pérola apresentaram elevados valores. Em contrapartida o desempenho insatisfatório do IAPAR 81 para CR e MSR (Tabela 3) se deve a baixa capacidade de expansão radicular deste genótipo, em busca de água nos perfis mais profundos do solo evidenciando ser este sensível a condições de escassez de água. Barbosa et al. (2000) observaram uma redução no comprimento radicular em espécies de Lenho em condições de estresse hídrico, e esta não é uma característica desejável.

O déficit de umidade ocorrido no florescimento provocou reduções na produção de grãos na cultura do feijão, sendo que, este foi mensurado a partir do NLP e NGL, visto que, quanto menor a redução dessas variáveis em condições de estresse, maior o potencial de rendimento das cultivares e estas podendo ser referidas como tolerantes ao estresse hídrico (GARRIDO, 1998), como é o caso dos genótipos Pérola e IPR Chopim.

Resultados obtidos por Aguiar et al. (2008) mostram que a supressão hídrica, ocorrida durante as fases de florescimento, ocasionou redução na maioria das características avaliadas, evidenciando a suscetibilidade de genótipos de feijão ao estresse hídrico, neste estádio de desenvolvimento. Sendo que, os genótipos que não sofrerem grandes reduções das características estudadas nessas condições, devem ser classificados com tolerantes ao estresse hídrico. É possível verificar que os genótipos IAPAR 81 e Pérola são contrastantes quanto aos efeitos ocasionados pela falta de água, estando em grupos distintos, visto que, foram estes os que apresentaram os piores e os melhores desempenhos respectivamente para a maioria das características avaliadas.

Independente da magnitude do estresse hídrico, genótipos de feijão respondem de maneira diferenciada ao déficit de água no solo durante o período da floração (MOLINA et al., 2001). E por este fato os genótipos puderam ser caracterizados como tolerantes ou sensíveis a falta de água.

A caracterização morfológica e o agrupamento de genótipos utilizando recursos de análise multivariada têm contribuído efetivamente para o melhoramento genético de várias culturas (SANTOS et al., 2000), possibilitando identificar a dissimilaridade ou não entre os genótipos. A capacidade de tolerar o estresse hídrico devido a superioridade que apresentou para as características avaliadas proporcionou ao Pérola grande dissimilaridade do IAPAR 81 e do IPR Juriti (Figura 1) devido o desempenho inferior que estes obtiveram. Tal dissimilaridade entre estes genótipos não foi observada na Figura 2, evidenciando que em condições ideais de desenvolvimento, suas composições gênicas não 
proporcionam diferença entre eles, visto que, situaram-se no mesmo grupo. O agrupamento em chaves distintas do Pérola com os genótipos IAPAR 81 e IPR Juriti é devido à expressão gênica diferencial do Pérola em condições de estresse hídrico que lhe proporcionou superioridade.

A partir dos resultados foi possível concluir que:

- o caráter diâmetro do caule não discriminou os genótipos de feijão em tolerantes e sensíveis a falta de água.

- o genótipo Pérola mostrou-se superior para a maioria das características avaliadas sendo classificado como tolerante ao estresse hídrico no período do florescimento, devendo ser incluído em blocos de cruzamentos de programas de melhoramento.

- os genótipos IAPAR 81 e IPR Juriti apresentaram resultados inferiores para a maioria das características avaliadas sendo classificado como sensíveis ao estresse hídrico no período do florescimento.

\section{Agradecimentos}

Agradecemos a UDESC, a CAPES e a FAPESC, pela concessão de bolsa e apoio financeiro e ao Instituto Agronômico do Paraná (IAPAR), na pessoa do Dr. Marco Antônio Lolatto pela colaboração na obtenção das sementes.

\section{Referências}

ACOSTA-GALLEGOS, J. A.; ADAMS, M. W. lant traits and yield stability of dry bean (Phaseolus vulgaris L.) cultivars under drought stress. Journal of Agricultural Science, Cambridge, v. 116, n. 2, p. 213-219, 1991.

AGUIAR, R. S.; MODA-CIRINO, V.; FARIA, R. T.; VIDAL, L. H. I. Avaliação de linhagens promissoras de feijoeiro (Phaseolus vulgaris L.) tolerantes ao déficit hídrico. Semina: Ciências Agrárias, Londrina, v. 29, n. 1, p. 1-14, 2008.

ARUNYANARK, A.; JOGLOY, S.; AKKASAENG, C.; VORASOOT, N.; NAGESWARA RAO, R. C.; WRIGHT, G. C.; PATANOTHAI, A. Association between aflatoxin contamination and drought tolerance traits in peanut. Field Crops Research, Weigang, v. 114, n. 1, p. 14-22, 2009.

BARBOSA, D. C. A.; NOGUEIRA, R. J. M.; MELO-FILHO, P. A. Comparative studies of growth in theree species os "caatinga" submitted to water stress. Phyton, Buenos Aires, v. 69, n. 1, p. 45$50,2000$.
BANZATTO, D. A.; KRONKA, S. N. Experimentação agrícola. Jaboticabal: FUNEP, 2006. 247 p.

BEEBE, S. E.; IDUPULAPATI, R. A. O.; MATTHEW, W. B.; BUTARE, L. Selection for drought resistance in common bean also improves yield in phosphorus limited and favorable environments. Crop Science, Madison, v. 48, n. 2, p. 582-592, 2008.

CONAB - Companhia Nacional de Abastecimento. Acompanhamento de safra brasileira: grãos, sétimo levantamento, abril 2010 / Companhia Nacional de Abastecimento. Brasília: Conab, 2010. 54 p.

COSTA, J. R.; PINHO, J. L. M.; PARRY, M. M. Produção de matéria seca de cultivares de milho sob diferentes níveis de estresse hídrico. Revista Brasileira de Engenharia Agrícola e Ambiental, Campina Grande, v. 12, n. 5, p. 443-450, 2008.

CUSTÓDIO, C. C.; VIVAN, M. R.; NUNES, R. C. A.; AGOSTIN, E. A. T. Tolerância cruzada induzida por choque térmico na germinação de semente de feijão. Revista Brasileira de Sementes, Londrina, v. 31, n. 1, p. 131-143, 2009.

GARRIDO, M. A. T. Respostas do feijoeiro às lâminas de água e adubação nitrogenada. 1998. 205 f. Tese (Doutorado em Fitotecnia) - Universidade Federal de Lavras, Lavras. 1998.

GUIMARÃES G. M.; STONE, L. F.; BRUNINI, O. Adaptação do feijoeiro comum (Phaseolus vulgaris L.) à seca. Revista Brasileira de Engenharia Agrícola e Ambiental, Campina Grande, v. 10, n. 1, p. 70-75, 2006.

HUGHES, D. F.; JOLLEY, V. D.; BROWN, J. C. Role for potassium in the iron-stress response mechanism of iron- efficient oat. Soil Science Society of America Journal, Madison, v. 56, n. 3, p. 830835, 1992.

IBGE. Grupo de Coordenação de Estatísticas Agropecuárias GCEA/IBGE, DPE, COAGRO. Levantamento Sistemático da Produção Agrícola. 2010. Disponível em < http://www.ibge.gov. br/home/estatistica/indicadores/agropecuaria/lspa/lspa_201003_5. shtm>. Acesso em: 21 agosto 2010.

MOLINA, J. C.; MODA-CIRINO, V.; JÚNIOR, N. S. F.; FARIA, R. T.; DESTRO, D. Response of common bean cultivars and lines to water stress. Crop Breeding and Applied Biotechnology, Viçosa, v. 1, n. 4, p. 363-372, 2001.

NESI, C. N.; GARCIA, A. A. F. Decomposição ortogonal de graus de liberdade de tratamentos utilizando variáveis auxiliares e o PROC GLM do SAS. Bragantia, Campinas, v. 64, n. 1, p. $157-$ 167, 2005.

OLIVEIRA, A. D.; FERNANDES, E. J.; RODRIGUES, T. J. D. Condutância estomática como indicador de estresse hídrico em feijão. Engenharia Agrícola, Jaboticabal, v. 25, n. 1, p. 86-95, 2005.

RAMALHO, M. A. P.; SILVA, G. S.; DIAS, L. A. S. Genetic plant improvement and climate changes. Crop Breeding and Apllied Biotechnology, Viçosa, v. 9, n. 2, p. 189-195, 2009.

ROHLF, F. J. NTSYS-pc: numerical taxonomy and multivariate analysis system, version 2.1. New York: Exeter Software, 2000. s/ paginação.

SANTOS, C. S. R.; MOREIRA, J. A. N.; FARIAS, R. H.; DUARTE, J. M. Classificação de genótipos de amendoim baseada nos descritores agromorfológicos e isoenzimáticos. Ciência Rural, Santa Maria, v. 30, n. 1, p. 55-59, 2000. 
SORATTO, R. P.; ORIVALDO, A. R. F.; RODRIGUES, R. A. F.; BUZETTI, S.; SILVA, T. R. B. Resposta do feijoeiro ao preparo do solo, manejo de água e parcelamento do nitrogênio. Acta Scientiarum: Agronomy, Maringá, v. 25, n. 1, p. 89-96, 2003.

SINGH, S. P. Selection for water-stress tolerance in interracial populations of common bean. Crop Science, Madison, v. 35, n. 1, p. 118-124, 1995.

SOUSA, M. A.; LIMA, M. D. B.; SIMON, G. A.; ANDRADE, J. W. S. Efeito do estresse hídrico na densidade do comprimento radicular em estádios de desenvolvimento do feijoeiro. Pesquisa Agropecuária Tropical, Goiânia, v. 39, n. 1, p. 25-30, 2009.
VIBRANS, A. C.; SCHRAMM, V. F. Perfil temporal de EVI/NDVI na bacia hidrográfica do rio Itajaí em Santa Catarina. In: SIMPÓSIO BRASILEIRO DE SENSORIAMENTO REMOTO, 14, 2009, Natal. Anais... São José dos Campos: INPE, 2009. p. 1581-1588. DVD, On-line. ISBN 978-85-17-00044-7. Disponível em <http:// urlib.net/dpi.inpe.br/sbsr@80/2008/10.17.15.49>. Acesso em: 27 agosto 2010 . 